DEVELOPING RESEARCH AND PRACTICE

\title{
Video capture of clinical care to enhance patient safety
}

\author{
M B Weinger, D C Gonzales, J Slagle, M Syeed
}

Qual Saf Health Care 2004;13:136-144. doi: 10.1136/qshc.2002.4143

Experience from other domains suggests that videotaping and analyzing actual clinical care can provide valuable insights for enhancing patient safety through improvements in the process of care. Methods are described for the videotaping and analysis of clinical care using a high quality portable multi-angle digital video system that enables simultaneous capture of vital signs and time code synchronization of all data streams. An observer can conduct clinician performance assessment (such as workload measurements or behavioral task analysis) either in real time (during videotaping) or while viewing previously recorded videotapes. Supplemental data are synchronized with the video record and stored electronically in a hierarchical database. The video records are transferred to DVD, resulting in a small, cheap, and accessible archive. A number of technical and logistical issues are discussed, including consent of patients and clinicians, maintaining subject privacy and confidentiality, and data security. Using anesthesiology as a test environment, over 270 clinical cases ( 872 hours) have been successfully videotaped and processed using the system.
See end of article for authors' affiliations

Correspondence to: Professor M B Weinger, San Diego Center for Patient Safety, VA San Diego Medical Center (125A), 3350 La Jolla Village Drive, San Diego, CA 92161-5008, USA; mweinger@ucsd.edu

Accepted 1 October 2003
$\mathrm{H}$ uman factors research in other high risk fields has shown that the rigorous study of factors that affect job performance can reduce errors and enhance system safety and quality. ${ }^{1-6}$ Clinician investigators have begun to apply many of these techniques to research into patient safety. ${ }^{7}$ To improve patient safety, it is critical to understand how clinical systems actually work, what factors make them work well (or not so well), and why adverse events occur. An increasingly popular approach to understanding the nature of clinical work is naturalistic observation, either with real time observers (for example, ethnography ${ }^{8-11}$ or task analysis $^{12-14}$ ) or via video data recording and analysis. ${ }^{15-21}$ An advantage of video recording is the creation of a permanent record that can be analyzed offline as often as necessary. Many authors have described video recording of clinical care, primarily for purposes of clinician education or quality improvement. ${ }^{22-28}$ Current generation technologies permit the development of high quality, robust, portable video recording and analysis systems for collecting records of both routine and non-routine clinical care. This paper describes the creation of such a system for use in the study of patient safety in anesthesia ${ }^{29}$ and discusses the many technical and logistical impediments that needed to be overcome. Using the system described, over 270 clinical cases (872 hours) have been successfully videotaped.

\section{DESIGNING A DIGITAL VIDEO DATA COLLECTION SYSTEM}

Design requirements and system overview Design requirements

The first step in the design of any new system is to assess thoroughly the user needs that the system is intended to address. ${ }^{30}$ Based on several years of experience doing low fidelity analog videotaping in the operating room (OR), ${ }^{16}$ review of the available literature, and conversations with many domain and technical experts, we created a list of hardware and software design requirements (table 1 ) for our specific application-videotaping anesthesia patient care in the OR to capture and analyze deviations from optimal care. ${ }^{29}$ It should be noted that the video system design requirements and their relative importance will vary appreciably depending on the intended application. For example, compared with our application, the design requirements for videotaping clinicians performing similar clinical tasks on a realistic patient simulator in a simulation center are somewhat different from those needed for videotaping anesthesia patient care (table 2).

Videotaping in the operating room requires special design considerations. The OR is crowded-the confined space can be filled with up to a dozen people and even more equipment, thus constraining space for video equipment and observers. $^{3132}$ In addition, views from a single camera will frequently be obstructed. The OR is noisy - multiple sounds and voices can diminish audibility. ${ }^{32}$ To obtain a full understanding of clinical events, data from vital signs monitors and clinical records must be obtained concurrently with audio and video feeds.

\section{System overview}

Our clinical data collection system was specifically tailored to facilitate the observation, collection, management, analysis, review, and archiving of multimedia data collected from the anesthesia workspace in the OR (fig 1). However, it is expected that a similar system would be equally usable in other medical venues such as critical care units, emergency rooms, and trauma units. Data can be collected in real time from multiple video and audio sources. The video and vital signs data are collected concurrently with behavioral task analysis (clinical and non-clinical tasks performed moment to moment), ${ }^{12-14} 16$ psychological and procedural workload, and 
Table 1 Design requirements for our clinical video data analysis system*

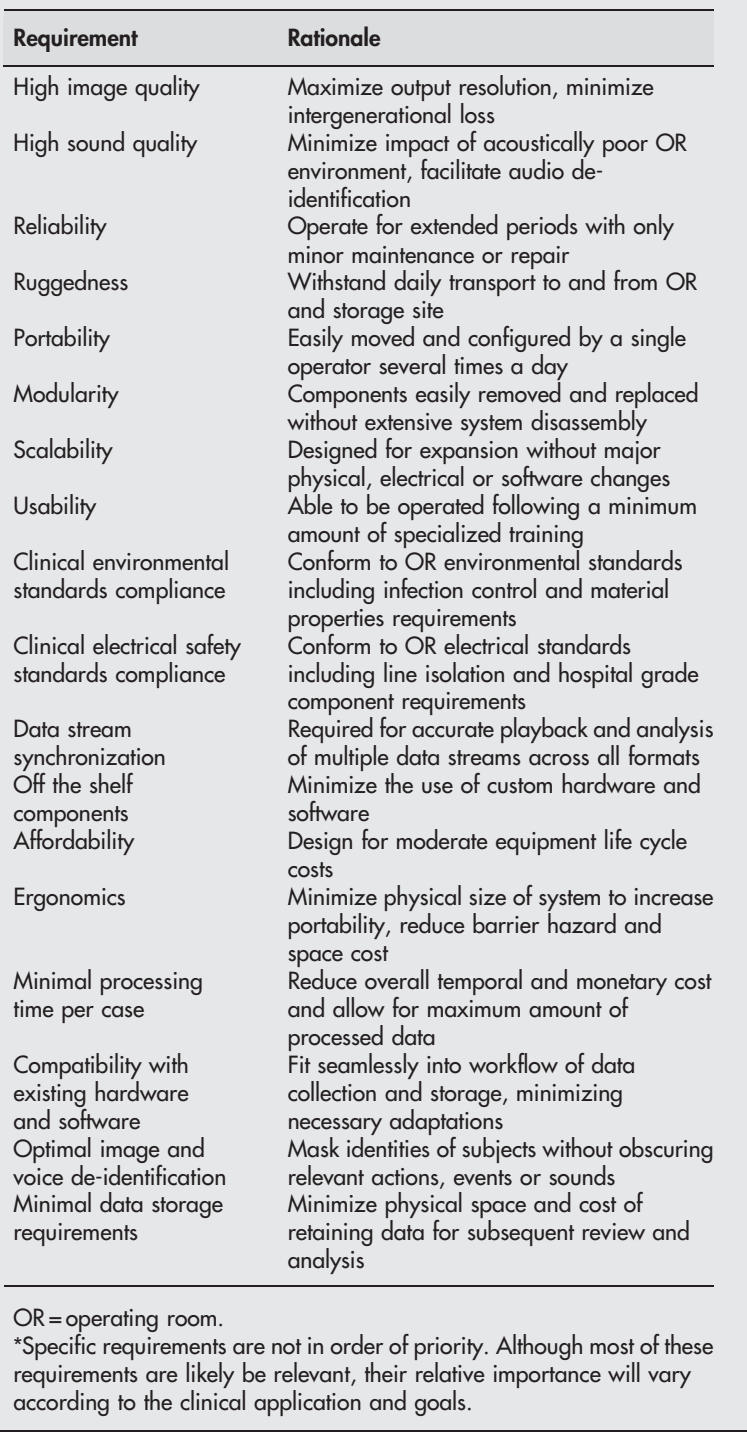

vigilance. ${ }^{12} 132934$ Information from an electronic anesthesia information system can also be captured. Each real time data stream is encoded with a common time code signal to facilitate subsequent analysis. Audio and video streams are processed and archived on DVD. These archived data can later be reviewed and analyzed by clinicians or researchers. Post-case analyses (such as annotations by clinical experts) can be stored on the DVD or in a parallel electronic research database that will be interfaced with the DVD archive. Clinician mood, sleep patterns, and demographics are obtained pre- and post-case. A post-case standardized survey instrument asks if any unusual clinical events occurred. ${ }^{7} 29$

\section{The video system \\ Cameras}

In our application, two cameras record the activities of the anesthesia care providers in the OR. The first camera is a high performance professional grade mini-DV camcorder. Audio and video signals are streamed directly to a video tape recorder (VTR) from the camera, eliminating the need for a high capacity tape magazine. This camera can automatically focus and control aperture setting and can zoom remotely via infrared signal. Pan and tilt functions are adjusted manually (although a remote controlled pan-tilt-zoom component could be attached). The camera can be mounted on a stationary tripod or telescoping monopod, either one positioned to capture the subjects from an eye level, side view perspective. The field of view can be narrowed sufficiently to exclude those personnel who are not study subjects.

The second camera is a high performance professional grade "unitized" security type camera. It can be rapidly engaged and disengaged from its mounting bracket and electrical connections with a simple twist (fig 1). It is possible to configure a clinical environment with several mounting brackets and rapidly relocate the camera as needs dictate. The video output from the camera is input to a VTR via the camera's switching and control circuitry. The camera controller, located in the video cart, allows control over 360 degrees of pan and 180 degrees of tilt, as well as zoom, aperture, and focus. This camera is either mounted on a monopod directly above and behind the anesthesia machine or wall mounted at ceiling height toward the periphery of the OR. Optimal positioning provides the best view of the anesthesiologist interacting with the patient while being unobtrusive, out of the way of other equipment, and not able to be disrupted during movement of the surgical lights.

\section{Video tape recorders (VTR) and patient vital signs data}

Three VTRs are used to record simultaneously and independently the two camera views and patient's physiological data. The patient's vital signs, as collected and displayed in each OR on a VGA computer monitor, are converted to high quality NTSC television format and recorded on a VTR. These professional quality recording and editing decks can record up to 3 hours of digital video per cassette. Each deck accepts two simultaneous better than CD quality stereo audio inputs, with the ability to aurally and visually monitor and adjust each channel in real time. The time code from an external time code generator can be written to the videotape. An alternative that may be suitable for some clinical applications would be the use of a video mixer to combine several video data streams (for example, two camera views) in real timeperhaps as a split screen image-and to record the resulting mixed signal onto a single VTR.

\section{Time code generation and data stream synchronization}

The goal is to create as accurate a record of clinical events as possible. To achieve this in the OR we concurrently collect two separate video data streams, four audio channels, patient's vital signs data, behavioral task analysis data, record keeping information, and direct observations entered into a laptop computer by a research assistant. To recreate what transpired, these various data streams must be replayed in synchrony. For audio tracks, even a delay of $1 / 30$ th of a second between two signals will create a detectable echo. Unfortunately, even the highest quality VTRs are subject to drift (due to age, mechanical condition, tape stretch, voltage variation, etc) over the duration of surgical procedures lasting many hours. Merely pressing "RECORD" simultaneously on the three separate VTRs is therefore insufficient. To accomplish the critical task of maintaining synchronization, a standard video time code is used (box l).

Our VTR was specifically selected because it could receive external time code signals. A time code generator, driven by a very stable electronic clock, sends a dropframe longitudinal SMPTE time code to the VTR and also produces an electronic time code that is sent via an RS-232 interface to our behavioral task observation and recordkeeping computers. Thus, even over a 6 or 8 hour clinical case, each synchronous 
Table 2 Comparison of some of the design requirements for an OR clinical video system with those of a simulation center*

\begin{tabular}{|c|c|c|}
\hline Requirement & Operating room & Simulation center \\
\hline Consent & Standard human subjects consent & $\begin{array}{l}\text { Standard video release (except for } \\
\text { research studies) }\end{array}$ \\
\hline High image quality & $\begin{array}{l}\text { Maximize output resolution, minimize } \\
\text { intergenerational loss }\end{array}$ & Same \\
\hline High sound quality & $\begin{array}{l}\text { Minimize impact of acoustically poor } \\
\text { OR environment, facilitate audio } \\
\text { de-identification }\end{array}$ & Better acoustical environment \\
\hline Reliability & $\begin{array}{l}\text { Operate for extended periods with only } \\
\text { minor maintenance or repair }\end{array}$ & Same \\
\hline Ruggedness & $\begin{array}{l}\text { Withstand daily transport to and from } \\
O R \text { and storage site }\end{array}$ & $\begin{array}{l}\text { Packaging requirements reduced since } \\
\text { equipment in fixed location }\end{array}$ \\
\hline Portability & $\begin{array}{l}\text { Easily moved and configured by a } \\
\text { single operator several times a day }\end{array}$ & $\begin{array}{l}\text { Reduced requirements since equipment in } \\
\text { fixed location }\end{array}$ \\
\hline $\begin{array}{l}\text { Clinical environmental } \\
\text { standards compliance }\end{array}$ & $\begin{array}{l}\text { Conform to OR environmental standards } \\
\text { including infection control and material } \\
\text { properties requirements }\end{array}$ & $\begin{array}{l}\text { Clinical environmental standards not } \\
\text { relevant. Material properties } \\
\text { requirements relaxed }\end{array}$ \\
\hline $\begin{array}{l}\text { Clinical electrical safety } \\
\text { standards compliance }\end{array}$ & $\begin{array}{l}\text { Conform to OR electrical standards } \\
\text { including line isolation and hospital } \\
\text { grade component requirements }\end{array}$ & $\begin{array}{l}\text { Conformation to OR electrical standards } \\
\text { generally unnecessary }\end{array}$ \\
\hline $\begin{array}{l}\text { Data stream } \\
\text { synchronization }\end{array}$ & $\begin{array}{l}\text { Required for accurate playback and } \\
\text { analysis of multiple data streams across } \\
\text { all formats }\end{array}$ & Same-important for effective debriefing \\
\hline Ergonomics & $\begin{array}{l}\text { Minimize physical size of system to } \\
\text { increase portability, reduce barrier } \\
\text { hazard and space cost }\end{array}$ & $\begin{array}{l}\text { Larger sizes tolerable. Barrier hazard } \\
\text { reduced }\end{array}$ \\
\hline $\begin{array}{l}\text { Minimal processing } \\
\text { time per case }\end{array}$ & $\begin{array}{l}\text { Reduce overall temporal and monetary } \\
\text { cost and allow for maximum amount } \\
\text { of processed data }\end{array}$ & Same \\
\hline $\begin{array}{l}\text { Optimal image and voice } \\
\text { de-identification }\end{array}$ & $\begin{array}{l}\text { Mask identities of subjects without } \\
\text { obscuring relevant actions, events or } \\
\text { sounds }\end{array}$ & Less critical since subjects are volunteers \\
\hline
\end{tabular}

frame of video as well as the other corresponding data elements has associated with it an identical time code number. All of the resulting recorded digital media can then be accessed synchronously during subsequent playback.

\section{Audio recording}

The audio system is designed as a series of four concentric zones, with the outermost zone being the least directional and the innermost being the most focused. A total of four
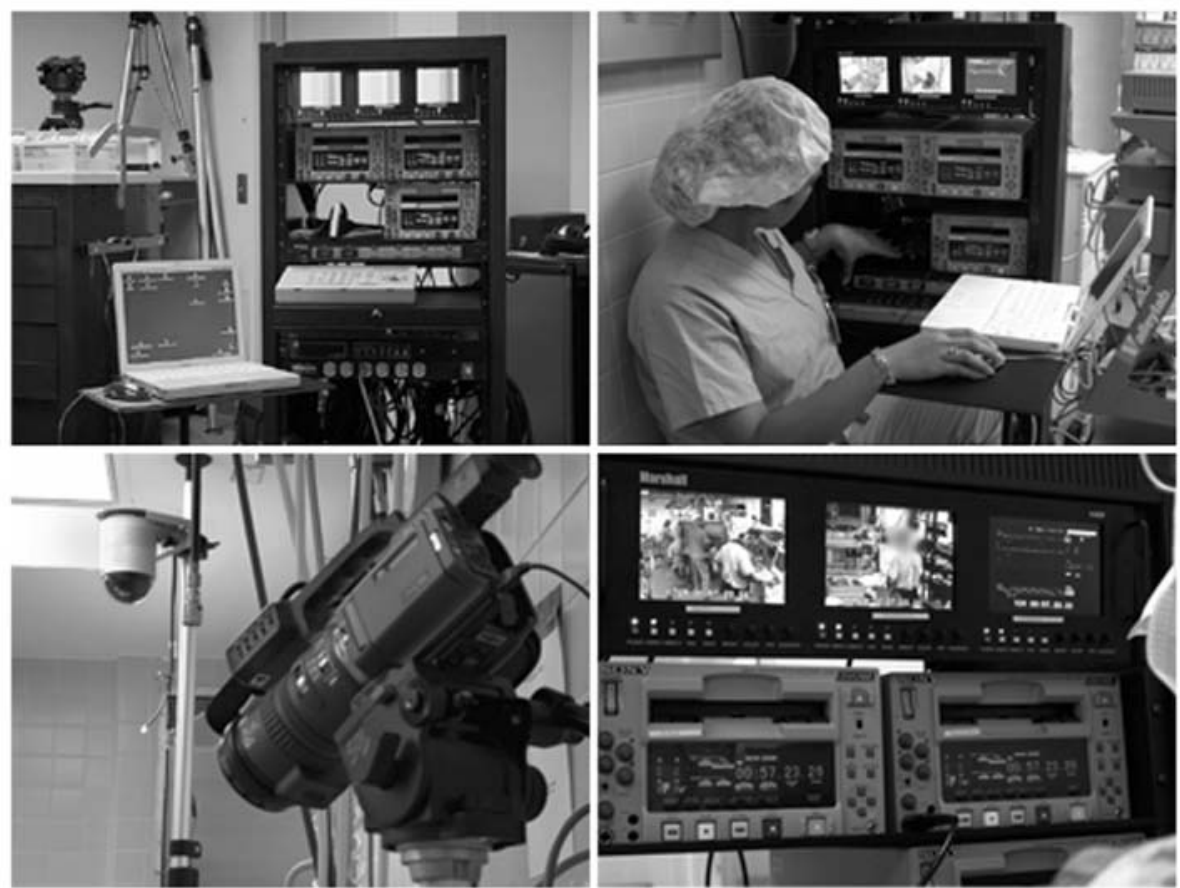

Figure 1 Clinical data collection system. Four views of our current data collection cart and associated video cameras. The data collection system includes three digital videotape recorders, two cameras, wireless and wired audio recording, time code synchronization, and a laptop computer running custom software for behavioral task analysis and clinical workload assessment. 


\section{Box 1 Understanding time codes}

The concept of time coding emerged to address the need to synchronize audio and film images to each other (so that the correct words were heard when the screen actor's lips moved). While initially performed mechanically via a series of holes in the film, the introduction of videotape required a different approach. The Society of Motion Picture and Television Engineers (SMPTE) developed a coding system (SMPTE time code) that assigned a unique time stamp to each video image (frame) and which was recorded to a separate audio track on the tape. A time code generator is simply an electronic clock that generates the SMPTE time code using 24 hour clock time in hours, minutes and seconds. Each second is further divided into 29.97 frames (in the US). The electronic time code can be encoded into a $2400 \mathrm{~Hz}$ audio tone and recorded on an audio track in synchrony with the video images, and also saved at a parallel rate of 29.97 frames per second (longitudinal time code). Alternatively, the time code can be recorded along the length of the videotape or be imbedded into the video signal itself (vertical interval time code, VITC). Certain formats, DV included, can additionally record the time code on its own dedicated track. Thus, as each frame of video is recorded to the tape, a unique time code number is recorded along with it. The next frame of video receives the next sequential time code, and so on.

As one might expect, there are actually several types of time code. For historical reasons, US broadcast television protocols specify an actual recording and broadcast rate of 29.97 frames per second. Since the time code runs at 30 frames per second, the time code generator must adjust itself by "dropping" a frame number (but not the actual video) at regular intervals in order to stay aligned with the slower video source. This is referred to as a dropframe time code system.

microphones are powered and preamplified, as required, then recorded individually on the VTR. No mixing of signals occurs before recording. This approach permits isolation of individual care providers' audio, enhancing the opportunity for appropriate auditory de-identification as needed.

At the outermost zone, audio can be recorded by a miniature omnidirectional microphone placed on top of the unitized camera mount to capture ambient sound. In the next zone, a super-cardioid microphone mounted on top of the camcorder captures audio in the immediate surroundings of the anesthesia care providers. A miniature cardioid microphone mounted on a gooseneck in the anesthesia monitoring array records the conversations of clinicians positioned adjacent to the anesthesia gas machine. Finally, wireless microphones are worn by the anesthesia resident and attending. The wireless microphone system uses lightweight body pack transmitters which send $10 \mathrm{~mW}$ UHF signals to the receiver section mounted in the cart. Highly unidirectional lavaliere microphones maximally isolate the audio from each care provider and minimize the potential for audio crosstalk. We have recorded over 500 hours of audio with these low power wireless transmitter-receiver systems in the operating room with no interference with the clinical equipment.

\section{Packaging the components}

With floor space in the OR at a premium, great effort was expended to design a system that occupies a minimal volume. Except for the cameras and microphones, all equipment was mounted with high security screws in a standard 19 inch wide, 22 inch deep rack mount wheeled cart (fig 1). The laptop computer used for behavioral task analysis can be placed on a pullout shelf, an articulated arm, or an independent stand. To comply with infection control and biomedical engineering regulations, materials such as wood, laminate, textiles or highly textured surfaces were avoided. Brackets were fabricated out of acrylic solid surfacing materials. System power was derived from a hospital grade isolation transformer, external plugs, and connections.

When deployed, audio, video, and power cables are positioned across the floor and covered with 27 inch wide vinyl matting allowing for safe passage of people and equipment. For a more permanent installation, adhesive backed plastic conduit is used to channel cabling to wall or ceiling mounted equipment. A new, smaller, even more portable data collection system is currently under development for use in other hospitals.

\section{VIDEO DATA PROCESSING}

Following case recording, the videotape is delivered to the post-production area for processing, including archiving, identification and capture of events of interest, and special treatment of audio and video (fig 2). This is followed, as desired, by expert analysis and synthesis of all data elements into a unified database.

\section{Data archiving}

The videotapes are recorded in groups of three-one videotape for the eye level view of the subjects, one for the elevated view, and one for the physiological vital signs. The digital videotapes are immediately archived to individual DVD discs via stand alone dedicated DVD recorders (fig 3A) that produce an MPEG-2 video stream on a standard DVDvideo format disc. DVD-R media was chosen for archiving because of the wide availability of compatible recorders and players, its low cost ( $\$ 1.88$ per hour for DVD versus $\$ 11.67$ for digital videotape), ruggedness, quality, portability, and small physical volume. In addition to supporting high quality MPEG-2 encoded video, the DVD-video standard permits multiple channel surround sound audio, a choice of screen format (wide, letterbox, and pan and scan), eight tracks of separate synchronized audio, menus and random access for user interactivity, up to nine camera angles, and digital and analog copy protection. Following archiving to DVD, the videotapes are generally erased and reused, which saves significant expense compared with purchasing fresh tapes for every case. If a tape contains an event of interest it can be retained as needed for treatment (see below).

The most noteworthy consequences of conversion to the MPEG-2 format are a slight degradation in image quality, the loss of SMPTE time code information, and the potential for audio drift. As the analog video signal is written to the VTR, it is compressed in a 5:1 ratio. Extensive testing of the trade off between video quality and storage requirements led to a decision to accept a small amount of additional compression in order to allow recording of 2 hours of MPEG-2 video per DVD. The effects of compression (blocky fields, digital noise on harsh edges, etc) are only visible during high motion and then only if viewed at reduced speed. Since extreme movement is not the norm for most clinical activities, the resulting digital video quality is still excellent and more than adequate for typical clinical applications. In fact, footage captured from and re-encoded to DVD still looks very good.

As the time code imprinted video is converted to MPEG-2, the time code numbers are replaced with corresponding digital video frame numbers. By recording this correspondence, data stream synchronization is maintained because there remains a one to one equivalence of frame number to system wide time code. This manual remapping of time code to frame number is possible due to the precision of digital 


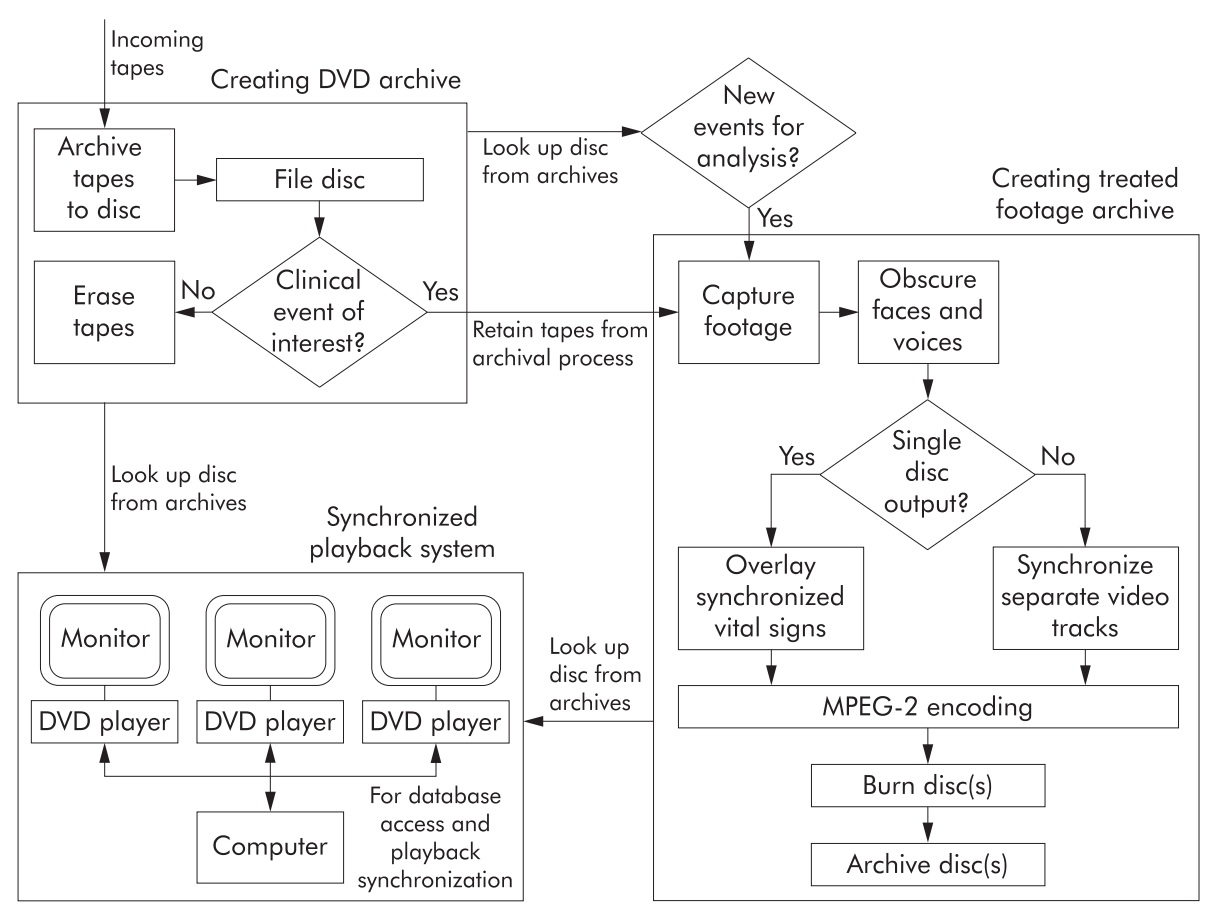

Figure 2 Flowchart of digital video processing and archiving. The figure shows the flow of clinical video data from initial collection through processing and archiving (see text for details).
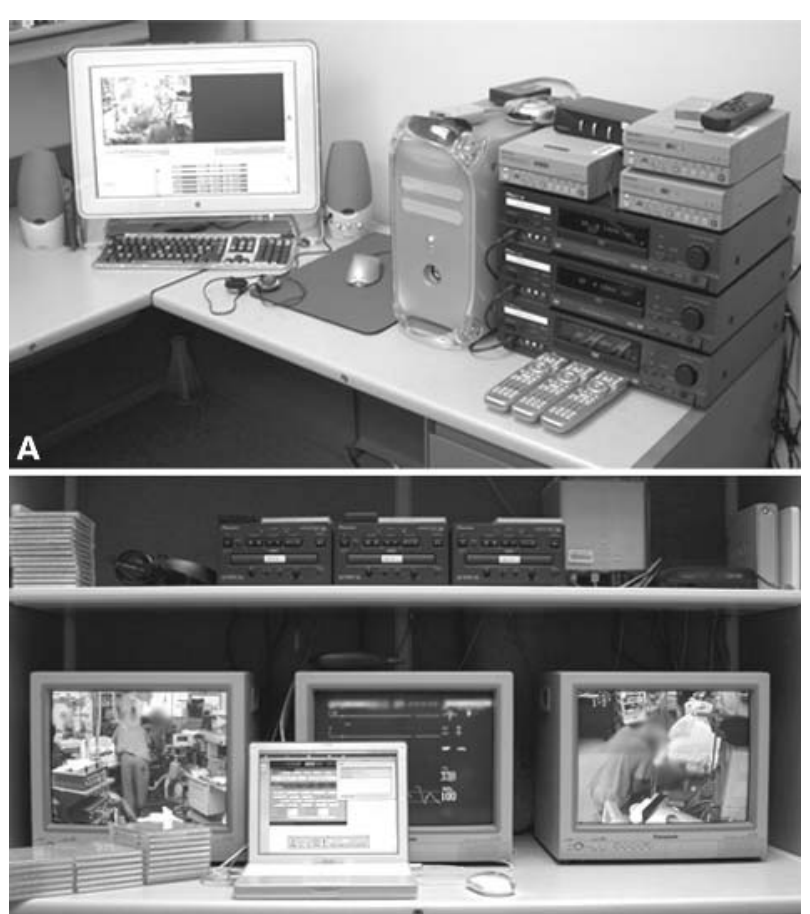

B

Figure 3 Digital video processing, archiving, and viewing stations. (A) DVD creation station (right) where three digital videotapes containing raw clinical video footage are burned directly to MPEG-2 encoded video on DVD. To the left is the non-linear digital video editing station, an Apple Macintosh dual processor G4 computer running commercially available software. (B) DVD review station. A computer running custom software controls three industrial grade DVD players attached to high quality color monitors. The review software permits synchronized playback of any case segment and annotative text entry (with associated case time) linked to our clinical event database. video-unfortunately, digital audio has never been quite as precise. Because digital audio is not defined as having a frame rate (instead using a much higher frequency sample rate), different manufacturers have devised different methods for maintaining audio and video synchrony. These methods are not always perfect over long periods and can also falter during format transfers (such as from DV to DVD). In practice, we have observed an audio drift of 2-4 frames after 2 hours of "synchronized" DVD playback. While noticeable as a slight echo during regular playback, audio drift can easily be corrected during processing and, in cases as minor as this, can be corrected with our playback software.

Identification and review of events of special interest Once clinical data have been collected on videotape, it is desirable for the clinicians involved in the case or expert reviewers to examine the available information to comment on the case or evaluate events of interest. This review is facilitated by the use of industrial grade DVD players that are controlled by a computer via custom software (fig 3B) which maintains data stream synchronization, corrects for irregular cases and tape errors, and allows for random access to specific times. Once identified, case segments of interest can be marked via the playback software, extracted, and exported to a computer-based non-linear editing system for further processing. In our specific application we identify case segments in which clinical events posed or could have posed a risk to patient safety. These are then analyzed in detail.

\section{Video post-processing}

Depending upon the particular study, it may be necessary to alter the audio and/or video signal-for example, for discussion at a quality improvement conference or presentation at a meeting of clinicians or researchers. Such uses might necessitate the obscuration of the video images or voices, or perhaps the use of a voice-over audio tract. Manipulations to footage captured from tape or DVD are accomplished with a digital non-linear editing station consisting of a desktop computer and specialized software such as Adobe Premier ${ }^{\mathrm{TM}}$ 
or Apple Final Cut Pro ${ }^{\mathrm{TM}}$ (fig 3A). Post-processing of clinical events of interest might include removal of specific case information (OR number, day/time), patient and clinician facial obscuration, excision of other identifying features (such as distinctive visual attributes or name badges), and the addition of image overlays (for example, vital signs on top of video images), subtitles, visible time codes or other visual cues, or voice-over audio tracts. Such processing can take up to 2 hours of technician effort and 2 hours of rendering time for each minute of recorded video!

There are several alternative techniques for accomplishing the de-identification task with each representing a trade off between the amount of technician effort and render time required versus the appearance of the final video. A mosaicstyle or blurry mask that retains the position and orientation of the head (as might be seen on televised "anonymous confessions") has the most pleasing appearance but requires a significant amount of time and effort to produce. The use of solid colored dots that track each face is more economical, especially for longer video segments. Additional issues that impact on the effort required include the number of faces/ items to be de-identified and the amount of subject movement. Automated tracking software can facilitate the deidentification process but requires distinctive visible markers on each head to be obscured. Such software is expensive and error-prone, meaning manual corrections are still required.

It is at this stage that the final video presentation format is created. In our system, the video can be formatted in a number of ways including superimposed, picture-in-picture, and split-screen programs as the need dictates. Most commonly, each of the three video streams is kept separate and replayed synchronously on DVD players to separate monitors (fig 3B). Alternatively, however, one can take advantage of the multiple angle capability of the DVD-video standard by combining all three video streams onto a single DVD. The streams are organized in parallel tracks and can be selectively played in their full resolution without loss of fidelity. A fourth video stream (the first "angle") presents a quad-divided picture of the other three streams. On playback the quad screen is presented by default, with the viewer able to select alternative angles and view each of the other individual streams upon request. The advantage of this approach is that it requires only one DVD player and monitor without the need for a computer or special software to maintain synchronization. The disadvantage is that the DVDs must be changed more frequently (for example, one might only be able to fit 30 minutes of clinical video onto a single DVD) and the image size in the primary quad display is rather small.

\section{Audio post-processing}

The final audio output is created in post-production. Because the four channels of audio are recorded on individual tracks (unmixed), we have the option of either recording each to a separate audio track on the DVD or creating one or more mixed monaural, stereo, or even surround sound tracks. Altering audio information to effect anonymity is technically more difficult than video image obscuration. The subject's voice must be irreversibly altered yet still remain intelligible. Specific references to other individuals (such as mention of the patient's name) or objectionable language must be masked or excised. Background conversation is subjected to the same treatment but this can mask or alter other relevant non-verbal background audio cues (such as alarm sounds). We have investigated a variety of digital audio filters and are currently researching several novel software solutions that may prove effective. As audio processing inherently degrades quality to some degree, any solution will benefit from very high quality audio signals that isolate to the extent possible the voices of the individuals of interest. The use of highly unidirectional individual lavaliere microphones (as discussed previously) is therefore extremely important when audio obscuration is a key requirement. In addition, the use of concentrically zoned audio recording may facilitate the use of sound cancellation technology to further isolate conversations.

\section{Expert review and analysis}

At various points in the archiving process, a clinician participant or expert may be asked to review the video information at a video review station (fig 3B) and provide guidance and/or commentary. For example, shortly after case capture an expert reviewer might view the raw video footage to determine whether or not an event of special interest has occurred, and what specific post-production processing should take place. Later, another expert might be asked to review the processed video and provide additional written or spoken commentary. This new information is collected via keyboard or microphone input to the controlling computer and transferred to an existing electronic database. Observational data, case information, electronic medical record data, and additional case details are integrated into the comprehensive database as well, with each data element linked to the video via frame number.

When playing back recorded video footage, three industrial grade DVD players are controlled by custom playback software (fig 3B). This software maintains synchronization across all three players, even over random access time jumps. Once the user has input the time code to DVD correspondence, the software understands time values in a variety of formats, including the original case time code and "disc relative" counter values. If the start of a specific disc was thrown a few frames off or otherwise became irregular during the archiving process, the software can be calibrated to compensate. With a built-in annotation module, reviewers may load and read or create comments in a case annotation file with each text entry automatically receiving a time code stamp relative to the current video frame. Annotation file entries can be double clicked to jump directly to the corresponding time code on all three DVDs. All annotation files and case information are stored in a format that ultimately will be compatible with the full event database, allowing import and export from both applications. Future versions of the program will also include seamless database integration as well as digital voice annotation capabilities.

\section{PRACTICAL ISSUES}

Building a video system is actually the easier of two essential tasks. The more difficult task is getting your hospital and clinicians to agree to let you videotape actual patient care. Before collecting video images of clinicians and patients, obstacles to overcome include issues of human subject consent, privacy, confidentiality, medicolegal concerns, and logistics. This section will discuss Institutional Review Board (IRB) approval, informed consent, video consent release, HIPAA issues, and post-case data management. We will not discuss logistical issues such as identifying "good" cases to study, scheduling, or finding space to set up equipment as these will largely be unique to each application and institution.

\section{Human subject approval and consent}

Obtaining IRB approval for videotaping patient care for research purposes is a substantial challenge. The IRB protocol must discuss in great detail the procedures for addressing the committee's justified concerns about protecting the rights of the research subjects (in our case, clinicians), patients, and "bystanders" (for example, those who may not be the subject of the research but may nonetheless be captured on videotape). Compared with someone approaching their IRB for the first time with a video based patient safety or quality 
research study, we have the advantage of a 12 year history of videotaping patient care in our operating rooms. However, in many hospitals there is an established protocol for videotaping some types of patient care such as trauma and neonatal resuscitations. This local experience can be used as justification for the viability and appropriateness of videotaping in other clinical settings in the same facility.

Any IRB protocol must address the risks to human subjects participating in the research. Although the risks of physical injury to patients or providers from videotaping patient care are negligible, the risks of psychological injury could be substantial and include violations of privacy and the distress associated with being filmed (the possibility of being filmed during an adverse event is discussed below). When videotaping providers, the researcher must minimize the risk of disrupting normal patient care. In our experience, videotaping is largely unobtrusive and, if done properly, there is little risk of it either interfering with the normal course of clinical care or inducing a Hawthorne effect-that is, changing clinicians' behavior because they are being observed. This is particularly true during actual clinical crises.

In our application, before collecting any data all anesthesia care providers involved in the case are formally informed of the purposes and procedures of the research project by a trained research assistant, and the anesthesia providers are asked to read and sign a very detailed IRB approved five page consent form. All participants and patients are also presented with a video release form that informs each subject of all possible uses of the video data as well as the option to have his/her face obscured.

In our research study, bystander clinicians such as surgeons and OR nurses do not give written informed consent because they are neither the direct subjects of the research nor the focus of the data collection process. However, they are all informed of the study and have the right at any time to request that all data collection cease and the study be terminated (this right has never been exercised in 10 years of data collection involving over 500 cases). Occasionally, other anesthesia providers provide relief breaks to consented subjects during a study case. We handle this through blanket quarterly consents of all clinicians likely to be in this situation.

The initial reaction of many IRBs may be to insist that all persons likely to appear on the video (including transient members of the team such as medical students or ancillary staff) provide written informed consent, even if they are not the subjects of the research study. This can be a serious impediment to proceeding since written consent must be prospective (before starting videotaping) and, even if only a single clinician fails or refuses to sign, the study cannot proceed. Also, if someone shows up unexpectedly who has not provided consent, the study would have to cease. Given that not everyone will want to participate in your study (we have a participation rate of about $90 \%$ ), the combinatorial mathematics will substantially reduce the probability of being able to study clinical teams.* Possible mitigating strategies might include a request for "waiver of informed consent", $\dagger$ performing the study as a quality improvement

*If you have an average $90 \%$ participation rate and the average size of the clinical team to be studied is 8 , you have a $43 \%$ chance of getting all clinicians to consent to participate $\left((0.9)^{8}\right)$.

†Federal regulations governing informed consent (CFR §46.116(d)) clearly provide for a waiver of consent when: (1) the research involves no more than minimal risk to the subjects; (2) the waiver or alteration will not adversely affect the rights and welfare of the subjects; (3) the research could not practicably be carried out without the waiver or alteration; and (4) whenever appropriate, the subjects will be provided with additional pertinent information after participation.
Box 2 Lessons learned: designing a clinical video system

- Select an appropriate video media format $(8 \mathrm{~mm}$, VHS, DVCPro, etc), technology (tape, DVD, hard disk), and signal format (composite, S-Video, component, IEEE 1394) and adhere to them. Regardless of the specific implementation, it is important to try to select components that are designed to work primarily with each other. Be aware that, while some manufacturers claim to support multiple formats, the price one pays for that "flexibility" is offen a reduction in capability or features. This can result in a loss of quality or data.

- Use a single manufacturer's products. While not always possible, using a single manufacturer reduces the likelihood of incompatibility between components that necessitates conversion from one format to another which generally results in a reduction in data quality.

- Use "professional" quality equipment. While prices are appreciably higher, when viewed in the long term, professional quality equipment is a better investment than consumer grade equipment. Professional equipment is built for those who use their products on a daily basis and demand reliability. The components are more rugged and built with better quality materials (magnesium versus plastic housings, etc). The warranties are generally longer and technical support is better. Repairs can often be made locally, minimizing downtime compared with having equipment shipped elsewhere for service.

- Design your system for your target audience. Know who will be watching your videos and what their expectations are. Know how they will be viewing and using the final product. It would be unsatisfactory, for example, to prepare video for a web streamed production yet view it on a broadcast quality monitor.

- Know who your subjects are and who they are not. Even if not mandated, it is advisable to obtain the consent from all persons who will appear in the final production, as well as those who might appear. Importantly, know who your subjects are not and design your system to exclude them as much as is feasible (narrow fields of view and focused microphones).

- Know who will be operating the system and design for ease of use. Sophisticated complex machinery in the hands of an untrained operator may yield even poorer results than poor quality equipment in the hands of an expert. Usability must be considered at each stage of the design. Frequent input from, and hands-on testing with, the operators will reduce unpleasant surprises after the final system is assembled and in daily use.

- Follow standard engineering design protocol. Concept validation, prototype development, comparative component analysis, iterative user centred design, and field testing before final production are necessary steps to effective system design.

project, and/or complete and immediate de-identification of the videotapes and related data before review. This is a complex and controversial issue and the best advice is to contact the IRB Chair early in the planning process to determine what approaches will be feasible. 


\section{Key messages}

- Success in videotaping actual patient care, whether for research or quality improvement purposes, requires deliberate care and planning. The quality of the results is heavily influenced by the quality of the audio and video images obtained.

- Digital video hardware and soffware have many advantages over older analog technologies, especially for post-processing and analysis.

- Keys to an effective technical solution include early delineation of design requirements, the engagement of appropriate technical expertise, and careful evaluation of available hardware and software products.

- Processes for editing, analyzing, and archiving the resulting video data are as important as the initial video collection system.

- Before videotaping clinical care, the issues of human subject consent, patient and clinician privacy and confidentiality, medicolegal concerns, and practical logistics must be addressed.

\section{Confidentiality and privacy}

Each case studied is given a randomly generated unique code number to assure anonymity. To ensure confidentiality, all names and identifiable information of the care providers and patients, as well as dates and times, are stripped from all of the data records. Videotapes and DVDs are stored in a locked file, itself located in a locked laboratory room. All computers containing research data are in secure areas and are only accessible by authorized personnel through two levels of strong password protection.

Video images of patients' faces are considered "individually identifiable health information". The video images therefore are legally considered Protected Health Information (PHI) and thus are protected by the Privacy Rule of the Health Insurance Portability and Accountability Act of 1996 (HIPAA). ${ }^{35}$ Therefore, as of 14 April 2003, all patients whose providers participate in the research are asked to read and sign an authorization form that includes a description of the PHI to be obtained in our research, and explicitly states the patient's right to revoke this authorization.

\section{Medicolegal issues}

If an adverse event were to occur during a study case, then the videotape represents a record that could include "damning" evidence. Hospital administrators and potential clinician subjects will therefore invariably insist that all possible steps are taken to protect the data from medicolegal discovery. In addition, the IRB will consider this a tangible risk to research subjects that requires risk management. While some may argue that the new era of error disclosure would mandate free access of patients to any video recordings of their care, when doing patient safety research the need to ensure subject confidentiality, privacy, and to reduce risk of harm to voluntary consenting research subjects will tend to push in the opposite direction.

When conducting patient safety research that involves the collection and use of video data, we strongly recommend fully researching the nature and details of the liability coverage of the medical institution in which video data are being collected. In our hospitals, all clinicians are employees and thus are covered by blanket hospital policies. A second layer of legal protection can come from incorporating the videotaping process into the institution's established performance improvement or quality assurance programs. If structured properly, this can provide protection through statutory evidence codes. In California, hospital quality assurance programs are protected from the medicolegal discovery process through California Evidence Code sections 1156 and 1157.* However, care must be taken how the resulting data are used-sharing QA data outside the hospital's established medical staff committee processes could potentially result in a loss of protection from legal discovery. Research done under federal grant or contract can also receive confidentiality protection-for example, with a federal Certificate of Confidentiality in accordance with the provisions of Section 301(d) of the Public Health Service Act (42 U.S.C. \$24l(d)). The confidentiality of data stemming from research funded by the Agency for Healthcare Research and Quality (AHRQ) is protected through federal enabling legislation (42 U.S.C. § 299 et seq): "The confidentiality statute that is part of AHRQ's authorizing legislation, grounded in judicially recognized public policies intended to foster participation in and the conduct of research, provides a respected form of Federal statutory protection for all identifiable data submitted to the Agency, its grantees and contractors...". $†$ Regardless of this, it is critical that all potential concerns and issues of the participating clinicians and institutions are addressed and that they are fully informed of the details of the legal protection of the video data before agreeing to take part in the research project.

\section{CONCLUSION}

This paper describes a methodology for videotaping actual patient care using a custom digital video data collection and analysis system that employs largely off the shelf hardware. Early delineation of design requirements, skilled technical support, and careful consideration of the many issues and trade offs are essential for successful system implementation. Off the shelf post-production software permits editing, archiving, and management of video data; this process can be quite resource intensive. Analysis of videotapes is even more time consuming and commercially available software may not meet the needs of all clinical applications. We had to develop custom software to display, analyze, and link our video data to other concurrently collected data-for example, behavioral task analysis and workload data. Some of the lessons learned in designing our clinical video system are shown in box 2. Although not discussed in this paper, the analysis of video data requires rigorous methods to assure high data integrity and reliability (for more information, the reader is referred to some of the prior literature in this $\operatorname{area}^{15} 1624{ }^{36}{ }^{37}$ ). The information provided in this and other literature should assist in the use of this valuable patient safety research technique.

\section{ACKNOWLEDGEMENTS}

The authors thank the following who have provided technical advice: J Cormican, T Griffen, D Hanson, G Jansky, J Maller, J V Reynolds, B Semelsberger, J Stappard, and D Worswick. Additional thanks go to K Ruberg, K Vo, and L Zhou. Data collection would not have been possible without the efforts of A Groom and Z Torres, the consent of our anesthesia residents, anesthesia attendings, and nurse anesthetists, and the indulgence of our surgeons and operating room nurses.

*"Section 1157 represents a legislative choice between competing public concerns. It embraces the goal of medical staff candor at the cost of impairing plaintiffs' access to evidence." (Matchett $v$ Superior Court (1974), 40 Cal.App3d 623, 628-629).

†Memorandum by Susan Greene Merewitz, Senior Attorney for the Agency for Healthcare Research and Quality (AHRQ), 16 April 2001. Available at: http://www.ahrq.gov/fund/datamemo.htm. 


\section{Authors' affiliations}

M B Weinger, D C Gonzales, J Slagle, M Syeed, Anesthesia Ergonomics Research Laboratory of the San Diego Center for Patient Safety, Veterans Affairs San Diego Healthcare System, and the Department of Anesthesiology, University of California, San Diego, USA

This work was supported by grants to Dr Weinger from the Department of Veterans Affairs (HSR\&D IIR 20-066) and the Agency for Healthcare Research and Quality (RO1-HS11375 and P2O-HS1 1521).

Presented at the Video as Research Data Conference, Baltimore, Maryland, 30 September 2002, sponsored by the Agency for Healthcare Research and Quality.

\section{REFERENCES}

1 Bellenkes AH, Wickens CD, Kramer AF. Visual scanning and pilot expertise: the role of attentional flexibility and mental model development. Aviat Space Environ Med 1997:68:569-79.

2 Roth EM, Woods DD. Aiding human performance: I. Cognitive analysis. Le Travail Humain 1988;51:39-64.

3 Seamster TL, Redding RE, Cannon JR, et al. Cognitive task analysis of expertise in air traffic control. Int J Aviat Psychol 1993;3:257-83.

4 Wickens CD. Engineering psychology and human performance, 2nd ed. New York: Harper Collins, 1992.

5 Woods D, Wise J, Hanes L. An evaluation of nuclear power plant safety parameter display systems. Proc Hum Factors Soc 1981;25:110-4.

6 Woods DD, Cook RI, Billings CE. The impact of technology on physician cognition and performance. J Clin Monit 1995;11:5-8.

7 Weinger MB, Slagle J, Jain S, et al. Retrospective data collection and analytical techniques for patient safety studies. J Biomed Informatics 2003;36:106-19.

8 Coiera $\mathrm{E}$, Tombs V. Communication behaviours in a hospital setting: an observational study. BMJ 1998;316:673-6.

9 de Leval MR, Carthey J, Wright DJ, et al. Human factors and cardiac surgery: a multicenter study. J Thorac Cardiovasc Surg 2000;1 19:661-72.

10 Patterson ES, Cook RI, Render ML. Improving patient safety by identifying side effects from introducing bar coding in medication administration. J Am Med Inform Assoc 2002;9:540-53.

11 Taxis K, Barber N. Ethnographic study of incidence and severity of intravenous drug errors. BMJ 2003;326:684.

12 Weinger MB, Herndon OW, Gaba DM. The effect of electronic record keeping and transesophageal echocardiography on task distribution, workload, and vigilance during cardiac anesthesia. Anesthesiology 1997;87:144-55.

13 Weinger MB, Herndon OW, Paulus MP, et al. Objective task analysis and workload assessment of anesthesia providers. Anesthesiology 1994:80:77-92.

14 Fraind DB, Tubbesing V, Hughes S, et al. Task analysis of intravenous drug and fluid administration in the operating room. Anesthesiology 2002:97:139-47.

15 Howard SK, Gaba DM, Smith BE, et al. Simulation study of rested versus sleep-deprived anesthesiologists. Anesthesiology 2003;98:1345-55.

16 Slagle J, Weinger MB, Dinh $M-\Pi$, et al. Intra- and inter-rater reliability of a clinical task analysis methodology. Anesthesiology 2002;96:1129-39.

17 Weinger MB, Vora S, Herndon CN, et al. Evaluation of the effects of fatigue and sleepiness on clinical performance in on-call anesthesia residents during actual night time cases and in simulated cases. Proc Enhancing Patient Safety and Reducing Errors in Health Care. Chicago: National Patient Safety Foundation, 1999:306-10.

18 MacKenzie CF, Martin P, Xiao Y. Video analysis of prolonged uncorrected esophageal intubation. Anesthesiology 1996;84:1494-503.

19 Mackenzie CF, Craig GR, Parr MJ, et al. Video analysis of two emergency tracheal intubations identifies flawed decision-making. Anesthesiology 1994:81:763-71

20 Mackenzie CF, Jefferies NJ, Hunter WA, et al. Comparison of self-reporting of deficiencies in airway management with video analyses of actual performance. LOTAS Group. Hum Factors 1996;38:623-35.

21 Xiao Y, MacKenzie C, Orasanu J, et al. Information acquisition from audiovideo data sources: an experimental study on remote diagnosis. Telemed $J$ 1999;5: 139-55.

22 Andersen C, Adamsen L. Continuous video recording: a new clinical research tool for studying the nursing care of cancer patients. J Adv Nurs 2001:35:257-67.

23 Campbell LM, Sullivan F, Murray TS. Videotaping of general practice consultations: effect on patient satisfaction. BMJ 1995;311:236.

24 Cao CG, MacKenzie CL, Ibbotson JA, et al. Hierarchical decomposition of laparoscopic procedures. Stud Health Technol Inform 1999;62:83-9.

25 Hoyt DB, Shackford SR, Fridland PH, et al. Video recording trauma resuscitations: an effective teaching technique. J Trauma 1988;28:435-40.

26 Mann FA, Walkup RK, Berryman CR, et al. Computer-based videotape analysis of trauma resuscitations for quality assurance and clinical research. J Trauma-Injury Infect Crit Care 1994;36:226-30.

27 Menahem S, Julian JC, Skoroplas A, et al. Video recording in paediatric medicine-technique and educational benefits. J Audiov Media Med 1984;7:124-6.

28 Weston CF, Richmond P, McCabe MJ, et al. Video recording of cardiac arrest management: an aid to training and audit. Resuscitation 1992;24:13-15.

29 Weinger MB, Slagle J. Human factors research in anesthesia patient safety: techniques to elucidate factors affecting clinical task performance and decision making. J Am Med Inform Assoc 2002;9(Suppl):58-63.

30 AAMI Human Factors Committee. The human factors design process for medical devices. ANSI/AAMI HE-74:2001. Arlington, VA: Association for the Advancement of Medical Instrumentation, 2001:38.

31 Loeb R, Weinger MB, Englund CE. Ergonomics of the anesthesia workspace. In: Ehrenwerth J, Eisenkraft JB, eds. Anesthesia equipment: principles and applications. Malvern, PA: Mosby Year Book, 1993:385-404.

32 Weinger MB, Smith NT. Vigilance, alarms, and integrated monitoring systems. In: Ehrenwerth J, Eisenkraft JB, eds. Anesthesia equipment: principles and applications. Malvern, PA: Mosby Year Book, 1993:350-84.

33 Weinger $M$, Englund $C$. Ergonomic and human factors affecting anesthetic vigilance and monitoring performance in the operating room environment. Anesthesiology 1990;73:995-1021.

34 Vredenburgh AG, Weinger MB, Williams KJ, et al. Developing a technique to measure anesthesiologists' real-time workload. Proceedings of the IEA 2000/ HFES 2000 Congress 2000;44:4241-4.

35 Amatayakul M. Another layer of regulations: research under HIPAA. J Am Health Inform Manage Assoc 2003:16A-D.

36 Xiao Y, MacKenzie CF, Orasanu J, Spencer R, Gunawardane V, LOTAS. Visual scanning patterns during remote diagnosis. Proc Hum Factors Ergo Soc 1998;42:272-5

37 Fletcher GCL, Flin RH, McGeorge $\mathrm{P}$, et al. Anaesthetist's non-technical skills (ANTS): evaluation of a behavioural marker system. $\mathrm{Br} J$ Anaesth 2003;90:580-5. 